\title{
DIALEKTIKA ISLAM DAN BUDAYA LOKAL DALAM BIDANG SOSIAL SEBAGAI SALAH SATU WAJAH ISLAM JAWA
}

\author{
Andik Wahyun Muqoyyidin \\ Fakultas Agama Islam Universitas Pesantren Tinggi Darul 'Ulum Jombang \\ Komplek PP. Darul Ulum Peterongan Jombang 61481. Telp. 082139699764 \\ email: andikwahyun_m@yahoo.com
}

Abstract

This article is to unravel the issue of dialectic of Islam and local culture in the social field as one face of Javanese Islam. Historically, Islam came to Indonesia there is a record seventh century $A D$, but there are also the states of the thirteenth century $A D$. This means that Islam has been a long time to adapt and dialogue with the culture, customs, attitudes and ways of thinking locals Indonesia. Moreover, many aspects of Islamic teachings that can be flexible so it can receive the local elements are in harmony with the teachings of Islam. The style of Islam in Java in many ways resembles Islam in South Asia. Kerala, the Malabar coast became an important area for the spice trade. Therefore, this area is also very likely to be a transit area for the purpose of trading with the merchants and simultaneously broadcast and Sufi Moslem are deliberately seeking new areas for development of Islam. For this reason, the face of Islam in Java is the result of dialogue and dialectic between Islam and local culture which then displays the face of Javanese Islam. In fact, Islam in Java is indeed not a single, not a monolith, and not simple. Among these are reflected in social relations syncretic Javanese Moslem community with other communities go naturally with the local knowledge base in the village community at large.

Artikel ini ingin mengurai persoalan dialektika Islam dan budaya lokal dalam bidang sosial sebagai salah satu wajah Islam Jawa. Secara historis, Islam datang ke Indonesia ada yang mencatat abad VII Masehi, tapi ada juga yang menyatakan abad XIII Masehi. Ini berarti Islam telah lama beradaptasi dan berdialog dengan budaya, adat kebiasaan, sikap dan cara berpikir penduduk 
lokal Indonesia. Terlebih lagi, banyak aspek dari ajaran Islam yang dapat bersifat fleksibel sehingga dapat menerima unsur-unsur lokal yang selaras dengan ajaran Islam. Corak Islam di Jawa dalam banyak hal menyerupai Islam di Asia Selatan. Kerala, di pantai Malabar menjadi daerah penting untuk perdagangan rempah-rempah. Oleh karena itu, daerah ini juga sangat mungkin menjadi daerah transit bagi kaum pedagang dengan tujuan perdagangan dan sekaligus menyiarkan Islam dan kaum sufi yang secara sengaja mencari daerah baru untuk pengembangan Islam. Karena itulah, wajah Islam di Jawa merupakan hasil dialog dan dialektika antara Islam dan budaya lokal yang kemudian menampilkan wajah Islam yang khas Jawa. Dalam kenyataannya, Islam di Jawa memanglah tidak bersifat tunggal, tidak monolit, dan tidak simpel. Di antaranya adalah tercermin dalam relasi sosial komunitas Islam Jawa sinkretis dengan masyarakat lainnya berjalan secara alamiah dengan mendasarkan pada kearifan lokal masyarakat desa pada umumnya.

Key words: dialectic of Islam, local cultural, social, Javanese Islam

\section{Pendahuluan}

Para ahli sejarah bersepakat, bahwa Islam datang di Jawa pada masa pemerintahan raja-raja Hindu. Keberadaan Islam di Jawa ditemukan dalam prasasti makam di Leran, Gresik, yaitu Fatimah binti Maimun, wafat tahun $1087 \mathrm{M}$, yang diidentifikasi sebagai keturunan nabi dan menjadi penyebar Islam di daerah Gresik. Prasasti ini memberikan bukti autentik bahwa Islam telah menyebar di Jawa, khususnya di Jawa Timur pada masa pemerintahan Hindu, tepatnya Raja Airlangga.

Jaringan perdagangan antara kerajaan-kerajaan Hindu-Budha dengan India Selatan dan dunia Timur Tengah tentunya sudah terjalin sedemikian kuat. Jaringan itu terbentuk antara lain adanya saling memenuhi kebutuhan masyarakat. Dari Timur Tengah dibawa berbagai produk seperti kain sutra, permadani dan kebutuhan rumah tangga lainnya, sedangkan dari Nusantara dibawa berbagai produk pertanian dan perkebunan seperti rempah-rempah. Demikian pula hubungan antara daratan Cina dengan Jawa dan Timur Tengah dengan India Selatan juga sudah terbentuk. Produk keramik Cina adalah contoh merebaknya hubungan perdagangan tersebut. Kepulauan Nusantara - khususnya Jawa - adalah daerah lintasan bagi pedagang timur dan Timur Tengah. Bagi pedagang Cina yang menuju ke barat akan melalui jalur ini, demikian pula pedagang yang akan ke timur juga melewati wilayah ini. Akibatnya, daerah-daerah pesisir Jawa menjadi daerah yang banyak disinggahi oleh para imigran, terutama kaum pedagang. Itulah sebabnya daerah pesisir menjadi ajang pertemuan berbagai tradisi, yang datang dari berbagai wilayah. 
Tidak dapat dipungkiri bahwa Islam di Jawa memang datang di wilayah pesisir pada zaman itu. Nama-nama pelabuhan, seperti Tuban, Gresik dan Surabaya sudah tidak asing lagi. Pelabuhan-pelabuhan ini menjadi daerah transit bagi kaum pedagang yang akan berdagang ke pusat kerajaan Majapahit, yaitu melewati Pelabuhan Surabaya, kemudian ke Sungai Brantas dan terus ke Majapahit. Lambat laun, mereka itu membentuk koloni-koloni untuk menetap dan menyebarkan keyakinan-keyakinan keberagamaannya.

Oleh karena itulah, wajah Islam di Jawa merupakan hasil dialog dan dialektika antara Islam dan budaya lokal yang kemudian menampilkan wajah Islam yang khas Jawa. Kenyataannya, Islam di Jawa memang tidak bersifat tunggal, tidak monolit, dan tidak simpel. Islam Jawa bergelut dengan kenyataan negara-bangsa, modernitas, globalisasi, kebudayaan lokal, dan semua wacana kontemporer yang menghampiri perkembangan zaman dewasa ini. Dalam konteks ini, respon kelompok-kelompok atau organisasi-organisasi Islam di Indonesia dan Jawa khususnya sangat variatif, mulai dari konservatif, moderat, liberal, radikal, hingga fundamentalis. Tulisan ini secara spesifik dimaksudkan mengkaji dialog dan dialektika antara Islam dan budaya lokal dalam bidang sosial sebagai wujud dari bagian tampilnya wajah Islam yang khas Jawa yang disebut dengan Islam Jawa.

\section{Masyarakat Jawa, Budaya, dan Keagamaannya}

Masyarakat adalah kesatuan hidup dari makhluk-makhluk manusia yang terikat oleh suatu sistem adat istiadat (Koentjaraningrat, 1996: 100). Masyarakat Jawa merupakan salah satu masyarakat yang hidup dan berkembang mulai zaman dahulu hingga sekarang yang secara turun temurun menggunakan bahasa Jawa dalam berbagai ragam dialeknya dan mendiami sebagian besar Pulau Jawa (Herusatoto, 1987: 10). Di Jawa sendiri selain berkembang masyarakat Jawa juga berkembang masyarakat Sunda, Madura, dan masyarakat-masyarakat lainnya. Pada perkembangannya masyarakat Jawa tidak hanya mendiami Pulau Jawa, tetapi kemudian menyebar di hampir seluruh penjuru nusantara. Program transmigrasi yang dicanangkan pemerintah mengakibatkan banyak ditemukannya komunitas Jawa di luar pulau Jawa. Masyarakat Jawa ini memiliki karakteristik tersendiri dibandingkan dengan masyarakat-masyarakat lainnya, seperti masyarakat Sunda, masyarakat Madura, masyarakat Minang, dan lain sebagainya.

Dengan perkembangan IPTEKS (ilmu pengetahuan, teknologi, dan seni) yang semakin gencar seperti sekarang ini, masyarakat Jawa tetap eksis 
dengan berbagai keunikannya, baik dari segi budaya, agama maupun tata krama. Namun demikian, pengaruh IPTEKS tersebut sedikit demi sedikit mulai menggerogoti keunikan masyarakat Jawa tersebut, terutama di kalangan generasi mudanya. Di kota-kota besar seperti Yogyakarta sudah banyak ditemukan masyarakat Jawa yang tidak menunjukkan jati diri ke-Jawa-annya. Mereka lebih senang berpenampilan lebih modern yang tidak terikat oleh berbagai aturan atau tradisi-tradisi yang justru menghalangi mereka untuk maju (Marzuki, 2006: 3).

Begitu juga pengaruh keyakinan agama yang mereka anut ikut mewarnai tradisi dan budaya mereka sehari-hari. Masyarakat Jawa yang menganut Islam santri, misalnya, lebih banyak terikat dengan aturan Islamnya, meskipun bertentangan dengan budaya dan tradisi Jawanya. Hal ini karena tidak sedikit tradisi-tradisi Jawa yang bertentangan dengan keyakinan atau ajaran Islam. Sebaliknya bagi yang menganut Islam abangan tradisi Jawa tetap dijunjung tinggi, meskipun bertentangan dengan keyakinan atau ajaran Islam. Sebagian besar masyarakat Jawa sekarang ini menganut agama Islam. Di antara mereka masih banyak yang mewarisi agama nenek moyangnya, yakni beragama Hindu atau Budha, dan sebagian lain ada yang menganut agama Nasrani, baik Kristen maupun Katolik. Khusus yang menganut agama Islam, masyarakat Jawa bisa dikelompokkan menjadi dua golongan besar, golongan yang menganut Islam murni (sering disebut Islam santri) dan golongan yang menganut Islam Kejawen (sering disebut Agama Jawi atau disebut juga Islam abangan). Masyarakat Jawa yang menganut Islam santri biasanya tinggal di daerah pesisir, seperti Surabaya, Gresik, dan lain-lain, sedang yang menganut Islam Kejawen biasanya tinggal di Yogyakarta, Surakarta, dan Bagelen (Koentjaraningrat, 1995: 211). Ketika Islam datang di daerah Jawa bagian selatan terjadi proses dialog dengan budaya lokal Jawa sehingga melahirkan model keberagamaan yang 'sinkretis' dengan menampilkan Islam yang berwatak dan bergaya Jawa yang sering disebut dengan Islam Abangan. Hal ini berbeda dengan watak Islam dari komunitas Jawa Tengah bagian utara (Pantura) yang dikenal dengan Islam Santri (Geertz, 1976: 14).

Hasil dari proses dialog dan dialektika antara Islam dengan budaya lokal Jawa, melahirkan perpaduan tata nilai Islam dan budaya Jawa dengan menampilkan dua model keagamaan, yaitu (Ridhwan, 2008: 5):

1. Islam Jawa yang sinkretis dengan melahirkan perpaduan antara unsur Hindu-Budha dengan Islam.

2. Islam yang Puritan atau model keagamaan dengan mengikuti ajaran agama secara ketat.

el Harakah Vol.14 No.1 Tahun 2012 
Sinkretisme Islam berkembang di Indonesia, khususnya Jawa, karena Islam yang datang di Indonesia adalah Islam yang telah banyak terpengaruh oleh unsur-unsur mistik dari Persia dan India yang mengandung unsur-unsur yang cocok dengan pandangan hidup tradisional orang Jawa pada waktu itu (Partokusumo, 1995: 265; Ridhwan, 2008: 6).

Masyarakat Jawa memiliki budaya yang khas terkait dengan kehidupan beragamanya. Menurutnya ada tiga karakteristik kebudayaan Jawa yang terkait dengan hal ini, yaitu (Simuh, 1996: 110):

1. Kebudayaan Jawa pra Hindu-Budha

Kebudayaan masyarakat Indonesia, khususnya Jawa, sebelum datangnya pengaruh agama Hindu-Budha sangat sedikit yang dapat dikenal secara pasti. Sebagai masyarakat yang masih sederhana, wajar bila nampak bahwa sistem animisme dan dinamisme merupakan inti kebudayaan yang mewarnai seluruh aktivitas kehidupan masyarakatnya. Agama asli yang sering disebut orang Barat sebagai religion magic ini merupakan nilai budaya yang paling mengakar dalam masyarakat Indonesia, khususnya Jawa.

2. Kebudayaan Jawa masa Hindu-Budha

Kebudayaan Jawa yang menerima pengaruh dan menyerap unsur-unsur Hindu-Budha, prosesnya bukan hanya sekedar akulturasi saja, akan tetapi yang terjadi adalah kebangkitan kebudayaan Jawa dengan memanfaatkan unsur-unsur agama dan kebudayaan India. Ciri yang paling menonjol dalam kebudayaan Jawa adalah sangat bersifat teokratis. Masuknya pengaruh Hindu-Budha lebih mempersubur kepercayaan animisme dan dinamisme (serba magis) yang sudah lama mengakar dengan cerita mengenai orang-orang sakti setengah dewa dan jasa mantra-mantra (berupa rumusan kata-kata) yang dipandang magis.

3. Kebudayaan Jawa masa kerajaan Islam

Kebudayaan ini dimulai dengan berakhirnya kerajaan Jawa-Hindu menjadi Jawa-Islam di Demak. Kebudayaan ini tidak lepas dari pengaruh dan peran para ulama sufi yang mendapat gelar para wali tanah Jawa. Perkembangan Islam di Jawa tidak semudah yang ada di luar Jawa yang hanya berhadapan dengan budaya lokal yang masih bersahaja (animismedinamisme) dan tidak begitu banyak diresapi oleh unsur-unsur ajaran Hindu-Budha seperti di Jawa. Kebudayaan inilah yang kemudian melahirkan dua varian masyarakat Islam Jawa, yaitu santri dan abangan, yang dibedakan dengan taraf kesadaran keislaman mereka.

Sementara itu Suyanto menjelaskan bahwa karakteristik budaya Jawa 
adalah religius, non-doktriner, toleran, akomodatif, dan optimistik. Karakteristik seperti ini melahirkan corak, sifat, dan kecenderungan yang khas bagi masyarakat Jawa seperti berikut: 1) percaya kepada Tuhan Yang Maha Esa sebagai Sangkan Paraning Dumadi, dengan segala sifat dan kebesaran-Nya; 2) bercorak idealistis, percaya kepada sesuatu yang bersifat immateriil (bukan kebendaan) dan hal-hal yang bersifat adikodrati (supernatural) serta cenderung ke arah mistik; 3) lebih mengutamakan hakikat daripada segi-segi formal dan ritual;4) mengutamakan cinta kasih sebagai landasan pokok hubungan antar manusia; 5) percaya kepada takdir dan cenderung bersikap pasrah; 6) bersifat konvergen dan universal; 7) momot dan non-sektarian; 8) cenderung pada simbolisme; 9) cenderung pada gotong royong, guyub, rukun, dan damai; dan 10) kurang kompetitif dan kurang mengutamakan materi (Suyanto, 1990: 144).

Pandangan hidup Jawa memang berakar jauh ke masa lalu. Masyarakat Jawa sudah mengenal Tuhan sebelum datangnya agama-agama yang berkembang sekarang ini. Semua agama dan kepercayaan yang datang diterima dengan baik oleh masyarakat Jawa. Mereka tidak terbiasa mempertentangkan agama dan keyakinan. Mereka menganggap bahwa semua agama itu baik dengan ungkapan mereka: "Sedaya agami niku sae (semua agama itu baik)". Ungkapan inilah yang kemudian membawa konsekuensi timbulnya sinkretisme di kalangan masyarakat Jawa (Marzuki, 2006: 5).

Masyarakat Jawa yang menganut Islam sinkretis hingga sekarang masih banyak ditemukan, terutama di Yogyakarta dan Surakarta. Mereka akan tetap mengakui Islam sebagai agamanya, apabila berhadapan dengan permasalahan mengenai jatidiri mereka, seperti KTP, SIM, dan lain-lain. Secara formal mereka akan tetap mengakui Islam sebagai agamanya, meskipun tidak menjalankan ajaran-ajaran Islam yang pokok, seperti shalat lima waktu, puasa Ramadlan, zakat, dan haji (Koentjaraningrat, 1994: 313).

Masyarakat Jawa, terutama yang menganut Kejawen, mengenal banyak sekali orang atau benda yang dianggap keramat. Biasanya orang yang dianggap keramat adalah para tokoh yang banyak berjasa pada masyarakat atau para ulama yang menyebarkan ajaran-ajaran agama dan lain-lain. Sedang benda yang sering dikeramatkan adalah benda-benda pusaka peninggalan dan juga makam-makam dari para leluhur serta tokoh-tokoh yang mereka hormati. Di antara tokoh yang dikeramatkan adalah Sunan Kalijaga dan para wali sembilan lainnya sebagai tokoh penyebar agama Islam di Jawa. Tokoh-tokoh lain dari kalangan raja yang dikeramatkan adalah Sultan Agung, Panembahan Senopati, Pangeran Purbaya, dan masih banyak lagi tokoh lainnya. Masyarakat Jawa percaya 
bahwa tokoh-tokoh dan benda-benda keramat itu dapat memberi berkah. Itulah sebabnya, mereka melakukan berbagai aktivitas untuk mendapatkan berkah dari para tokoh dan benda-benda keramat tersebut.

Masyarakat Jawa juga percaya kepada makhluk-makhluk halus yang menurut mereka berkeliaran di sekitar manusia yang masih hidup. Makhluk-makhluk halus ini ada yang menguntungkan dan ada yang merugikan manusia. Karena itu, mereka harus berusaha untuk melunakkan makhluk-makhluk tersebut agar menjadi jinak, yaitu dengan memberikan berbagai ritus atau upacara.

Di samping itu, masyarakat Jawa juga percaya akan adanya dewa-dewa. Hal ini terlihat jelas pada keyakinan mereka akan adanya penguasa Laut Selatan yang mereka sebut Nyai Roro Kidul (Ratu Pantai Selatan). Masyarakat Jawa yang tinggal di daerah pantai selatan sangat mempercayai bahwa Nyai Roro Kidul adalah penguasa Laut Selatan yang mempunyai hubungan dengan kerabat Mataram (Yogyakarta). Mereka memberi bentuk sedekah laut agar mereka terhindar dari mara bahaya (Koentjaraningrat, 1995: 347).

Itulah gambaran tentang masyarakat Jawa dengan keunikan mereka dalam beragama dan berbudaya. Hingga sekarang keunikan ini justru menjadi warisan tradisi yang dijunjung tinggi dan tetap terpelihara dalam kehidupan mereka. Bahkan dengan adanya otonomi daerah, masing-masing daerah mencoba menggali tradisi-tradisi semisal untuk dijadikan tempat wisata yang dapat menambah income bagi daerah yang memiliki dan mengelolanya.

\section{Dialektika Islam dan Budaya Lokal Jawa dalam Aktivitas Sosial}

Ada tiga metode penyebaran Islam, berdasarkan studinya terhadap cerita-cerita seputar islamisasi di Nusantara, yaitu oleh pedagang muslim dalam jalur perdagangan yang damai, oleh para da'i dan orang suci (wali) yang datang dari India atau Arab yang sengaja bertujuan mengislamkan orang-orang kafir dan meningkatkan pengetahuan mereka yang telah beriman dan terakhir dengan kekuasaan atau memaklumkan perang terhadap negara-negara penyembah berhala. Jadi, Islam disebarkan dengan cara perdagangan, pendakwah sufi dan politik (Graaf, 1989: 2).

Dari sekian banyak cara penyebaran Islam tersebut, kiranya yang paling dominan adalah pendapat yang menyatakan bahwa Islam disebarkan melalui perdagangan. Pendapat seperti ini diangkat oleh sarjana-sarjana barat khususnya Belanda. (Wertheim dalam Abdullah, 1989: 94-111; Pijnapel dalam Azra, 1999: xii). Namun demikian, ada beberapa sarjana Belanda yang meragukan mengenai teori perdagangan ini, seperti Van Leur (Taufiq Abdullah, 1989: 29 30) dan (Azra, 1994: 32). Menurutnya, teori ini lemah, sebab tidak mungkin 
Islamisasi dapat dilakukan secara besar-besaran oleh kaum pedagang dan perkawinan.

Di antara sejarawan Asia, seperti S.Q. Fatimi juga menyangkal teori perdagangan ini. Menurutnya bahwa Islam disebarkan justru oleh kaum pendakwah sufi dari wilayah Bengal. Hal ini terbukti dengan corak Islam yang bersifat mistik yang bersesuaian dengan sikap mistik masyarakat di kawasan ini sebelumnya (Wahid, 1982: 41; Azra, 1994: 33; Drewes dalam Ibrahim, 1989: 35-36; dan Ricklefs dalam Bizawie, 2002: xx).

Para sejarawan banyak yang menyokong mengenai teori da'i sufi, antara lain ialah Fatimi, John, dan Tjandrasasmita. Melalui temuan terhadap naskahnaskah lama di beberapa wilayah Jawa, ternyata banyak dijumpai naskah yang bertemakan penyebaran Islam melalui kegiatan sufistik. John begitu yakin bahwa penyebaran Islam dilakukan oleh kaum sufi. Sebab baginya sangat tidak mungkin Islam disiarkan secara besar-besaran oleh kaum pedagang yang motifnya ialah mencari keuntungan secara material. Islam tentu disebarkan oleh pengembara sufi, terutama di abad ke-13 M. Faktor keberhasilan kaum sufi di dalam proses islamisasi ialah kemampuan kaum sufi untuk mengadopsi "keyakinan lokal" menjadi bagian penting di dalam ritual-ritual Islam. Secara atraktif ajaran Islam dikemas dalam coraknya yang berdekatan dengan tradisi lokal, sehingga penyebaran Islam berwajah damai, menekankan pada aspek batin atau esoteris. Untuk membuktikannya, John mengkaji literatur lokal yang memiliki keterkaitan dengan para pengembara sufi yang diyakini oleh penduduk lokal Nusantara pada zaman pra Islam. Kemudian, doktrin kaum sufi tersebut menjadi simbol-simbol kerajaan yang berupa martabat-martabat raja-raja Melayu yang menggunakan simbol-simbol orang keramat (Mudzhar, 1990: 18; 2002: xx-xxxi).

Memang, tidak dapat dipungkiri bahwa catatan sejarah Islam di Jawa sangat tergantung pada teks-teks yang menggambarkan berbagai peristiwa di masa lalu, akan tetapi, bahan-bahan teks tersebut tak selalu dijumpai dalam kajian-kajian Islam awal di Jawa. Akibatnya, mau tidak mau haruslah mencari bahan-bahan perbandingan untuk membandingkan berbagai corak Islam di Nusantara dengan Islam di belahan lain. Untuk itu ditemukanlah wilayah bandingan tersebut yaitu Islam di wilayah India Selatan, khususnya Kerala sebagai sumber Islam yang memiliki kesamaan dengan Islam Arab dan Dekkan sebagai sumber orde keagamaan dan politik Indo-Persia. Islam di Jawa, ternyata menggabungkan kedua sumber tersebut, dengan cara mengambil sumber orde keagamaan dari Kerala 
dan sumber religio-politik atau kerajawian dari tradisi kerajaan Indo-Persia (Woodward, 2001: 81).

Corak Islam di Jawa dalam banyak hal juga menyerupai Islam di Asia Selatan (Malabar di barat dan Koromandel di timur). Kerala, di pantai Malabar menjadi daerah penting untuk perdagangan rempah-rempah. Daerah ini terkenal semenjak zaman Romawi. Oleh karena itu, daerah ini juga sangat mungkin menjadi daerah transit bagi kaum pedagang dengan tujuan perdagangan dan sekaligus menyiarkan Islam dan kaum sufi yang secara sengaja mencari daerah baru untuk pengembangan Islam. Jadi, sangat mungkin bahwa Islam telah datang di daerah ini sejak awal di Arab, bahkan beberapa saat setelah wafatnya Nabi Muhammad SAW. Kesamaan itu dapat dilihat dari sistem pendidikan madrasi, upacaraupacara keagamaan, seperti slametan dan bahannya seperti apem dan juga tata ritual berdasarkan kesamaan madzhab di dalam Islam (Woodward, 2001: 84). Kemiripan keagamaan dan sosial, serta apa yang dikenal sebagai jalinan perdagangan India Selatan dan Asia Tenggara mengesankan Kerala merupakan salah satu sumber Islam Jawa dan juga mungkin suatu model masyarakat muslim kawasan pantai (Woodward, 2001: 84). Sejarawan yang juga berpendapat seperti ini ialah Arnold, dalam pandangannya, Islam di Jawa memiliki kesamaan dengan Islam di Malabar dan Colomander, mengingat bahwa terdapat kesamaan madzhab antara dua wilayah ini (Arnold, 1977: 318).

Peran Indo-Persia terhadap corak Islam di Jawa juga sangat menonjol. Dalam hal ini bisa dilihat dalam berbagai sistem ritual seperti nama-nama bulan Jawa yang dinisbahkan kepada sistem bulan di Persia. Di Arab dikenal nama bulan Muharram, akan tetapi masyarakat Jawa justru menyebutnya sebagai bulan Suro atau bulan Asyuro. Dalam tradisi Jawa, bulan Suro adalah bulan tirakatan, sebagaimana tradisi di Persia yang menganggap bulan ini sebagai bulan bela sungkawa atas kematian cucu Nabi Muhammad, Husain, di padang Karbala akibat pertempuran dengan Muawiyah. Jadi tradisi Shi'ah juga dilakukan oleh masyarakat Jawa. Selain itu juga upacara maulid nabi yang dirayakan besar-besaran juga merupakan perluasan tradisi "pengkultusan" terhadap tokoh yang dianggap suci. Tradisi ini tidak ditemukan dalam tradisi Islam Timur Tengah (Arab) sejak awal.

Berbagai kegiatan ritual pada umumnya berisi acara doa selamatan yang isi doanya disesuaikan dengan keperluan. Hampir tiap bulannya terdapat kegiatan ritual yang bersifat rutin. Berikut ini beberapa potret aliran Islam 
Kejawen yang merupakan hasil dari proses dialog dan dialektika antara Islam dengan budaya lokal Jawa pada masyarakat Jawa bagian selatan khususnya Kabupaten Banyumas dan Cilacap serta menampilkan model keberagamaan Islam Jawa yang sinkretis.

\section{Sinkretisasi Ajaran Islam dengan Kebudayaan Lokal di Banyumas}

Secara geografis, Kabupaten Banyumas dan Cilacap termasuk wilayah provinsi Jawa Tengah bagian selatan yang sering disebut dengan "daerah merah”. Istilah daerah merah memberi makna bahwa kawasan Jawa Tengah bagian selatan merupakan sebuah komunitas yang sangat kental dengan tradisi Jawa yang diadopsi dari tradisi kerajaan Hindu-Budha yang penuh dengan mitologi yang bersumber dari keyakinan animisme dan dinamisme (Pemberton, 2003: 368-380).

Kekentalan tradisi masyarakat Jawa bagian selatan khususnya Kabupaten Banyumas dan Cilacap yang begitu kuat, menjadikan proses Islamisasi di daerah ini menampilkan corak dan langgam dari sistem keyakinan dan berbagai ekspresi keagamaan yang unik pula. Pada uraian terdahulu dijelaskan bahwa ketika Islam datang di daerah ini dan terjadi proses dialog dengan budaya lokal Jawa maka akan melahirkan model keberagamaan yang 'sinkretis' dengan menampilkan Islam yang berwatak dan bergaya Jawa yang sering disebut dengan Islam Abangan. Hal ini berbeda dengan watak Islam dari komunitas Jawa Tengah bagian utara (Pantura) yang dikenal dengan Islam Santri (Geertz, 1976: 14).

Salah satu produk dialog antara Islam dengan budaya lokal Jawa di Jawa Tengah bagian selatan adalah adanya komunitas Islam Blangkon yang hingga sekarang eksistensinya masih kuat di Desa Pekuncen, Kecamatan Adipala dan Kecamatan Kroya, Kabupaten Cilacap. Kabupaten Banyumas dan Kabupaten Cilacap merupakan dua kabupaten yang dulu adalah eks karesidenan Banyumas. Secara geografis, posisi Kecamatan Jatilawang, Kecamatan Adipala dan Kecamatan Kroya merupakan daerah kecamatan yang jauh dari ibukota Kabupaten Banyumas maupun Cilacap.

Tokoh leluhur yang menjadi panutan dan tempat mereka meminta sesuatu adalah Kiai Bonokeling yang makamnya menjadi sentral kegiatan ketika ritual Nyadran dilaksanakan. Aktivitas ritual lain adalah kegiatan selametan yang biasanya dilaksanakan pada setiap Jemuah Pon yang dilaksanakan di sebuah tempat yang bernama Pasemuan.

Menurut penuturan informan kunci yang bernama Ki Wiryatpada, dalam 
(Ridhwan, 2008: 7) sistem rekruitmen keanggotaannya bersifat kekerabatan yang dibaiat sejak masih kanak-kanak oleh salah satu dari Kiai Kunci. Model kepemimpinan kelompok Islam Kejawen ini bersifat turun temurun atas dasar kekerabatan. Sedangkan struktur kepemimpinan kelompok ini adalah dengan mengikuti model kepemimpinan struktur lurah (kepala desa) jaman dulu. Dalam hal relasi sosial antara kelompok ini dengan kelompok luar selama ini terjalin secara baik dengan mengedepankan sikap toleransi yang tinggi. Salah satu simbol identitas dari kelompok ini dapat dilihat dari segi pakaian yang berbeda dengan masyarakat lainnya yang biasanya dipakai ketika berlangsung aktivitas ritual. Bagi pengikut laki-laki berpakaian sarung hitam dan jas/baju hitam dengan Blangkon sebagai penutup kepala. Sedangkan untuk para ibu dengan menggunakan kebaya atau kemben model pakaian Jawa kuno.

Pandangan keagamaan komunitas Islam Blangkon sangat kental dengan tradisi agama orang Jawa. Sistem keyakinan mereka sangat jelas tergambar dari penuturan salah seorang tokoh (kesepuhan) aliran ini yakni Bapak Mulyareja dalam (Ridhwan, 2008: 10) yang menyatakan, "Menungso urip teng dunya niku nek mboten nyantri nggih nyandi". Pernyataan ini berarti bahwa, manusia hidup di alam dunia ini terbagi menjadi dua, yaitu nyantri dan nyandi. Dua istilah ini digunakan untuk memilah antara kelompok yang notabene muslim dengan pengamalan rukun Islamnya yang lima secara utuh yang sering mereka sebut dengan Islam lima waktu dan kelompok muslim yang pengamalan rukun Islamnya hanya tiga (syahadat, puasa dan zakat), tanpa melakukan shalat lima waktu. Karena itu istilah nyantri sama dengan "Islam lima waktu", sedangkan istilah nyandi lebih identik dengan "Islam tanpa shalat lima waktu". Nyandi berarti poros keyakinannya mendasarkan pada Punden yaitu tempat-tempat suci. Tempat yang paling dianggap suci adalah makam Kiai Bonokeling.

Seorang wakil Kiai Kunci, Wiryatpada menuturkan, "Kula niki nggih Islam, sanes Hindu sanes Budha". Ia percaya akan adanya Gusti Allah sebagai Tuhan, tempat di mana manusia meminta pertolongan. Ia juga percaya bahwa Muhammad sebagai Nabi dan Rasul Allah. Dengan jelas ia melafadkan shalawat Nabi Allahumma Shalli ala Sayyidina Muhammadin wa 'ala Ali Sayyidina Muhammadin. Semua umat Islam hakikatnya bergerak pada tujuan dan muara yang sama yaitu mencapai kebenaran hakikat yaitu kebenaran yang hanya milik Allah. Perbedaan dalam beribadah tidak lebih perbedaan dalam hal cara mencapai tujuan. Dalam beribadah seseorang perlu perantara antara lain dengan menyalakan dupa dan kemudian diberi pengantar doa oleh Kiai Kunci/wakil Kiai Kunci agar dapat dikabul oleh Yang Maha Kuasa. 
Syahadat atau "sadat" menurut lisan komunitas muslim kejawen hanya diucapkan pada saat melakukan perkawinan di depan penghulu (Petugas Pencatat Perkawinan dari Kantor Urusan Agama/KUA). Adapun puasa, sebagaimana puasa yang dilakukan kelompok santri, dilakukan pada bulan Ramadhan dengan mengikuti aturan waktu sebagaimana yang ditentukan oleh pemerintah. Namun demikian, sebagian para kesepuhan aliran ini masih mempercayai puasa sirrih yaitu "Ne srengenge lingsir lan wetenge kerasa perih" (kalau matahari sudah tergelincir dan perut terasa perih) maka ketika itu boleh berbuka puasa.

Menurut Kuswadi, dalam hidup di dunia ini "Sing penting urip golek selamet, carane aja mlanggar angger-angger/aturan-aturan," artinya, yang penting dalam hidup ini adalah mencari selamat dengan cara tidak melakukan pelanggaranpelanggaran. Dalam hidup ini, masih menurut Kuswadi, yang penting selametan. Yang dimaksud selametan di sini adalah memberikan persembahan (berupa tumpeng atau ambeng dan $d u p a$ ) kepada leluhurnya yang dipercaya bisa memberikan manfaat juga marabahaya dalam hidup. Dia mengatakan, "Asal munggah wonten panembahan nggih selametan doa selametan punopo mawon, nggih doa selametan kedah caosi shodaqoh wonten panembahan. Anak putu podo munjung misal kagem mantun anggenipun sakit" (Yang penting memohon kepada leluhur dengan selametan berdoa selametan apa saja, yaitu doa selametan dengan memberikan persembahan kepada leluhur. Anak cucu juga ikut serta misalnya untuk bisa sembuh dari sakit) (Ridhwan, 2008: 11).

Menurut Sumitro, "Wong urip ning dunya iki kudu mados ilmu kangge akhirat lan mados sangune gesang teng alam kelanggengan," artinya, seseorang hidup di dunia ini harus mencari/menggali pengetahuan untuk hidup di akhirat dan mempersiapkan bekal untuk hidup di alam yang kekal. Ibadahnya orang kejawen adalah selametan, misalnya: Nyadran (ritual tahunan yang dilaksanakan pada Bulan Ruwah), saben omah paring caos dateng Kiai Bonokeling (tiap rumah memberikan persembahan kepada Kiai Bonokeling), Muludan yang dilaksanakan di Adiraja dan selamatan lainnya. Menurut Istri Kiai Mejasari, "Wong kejawen $i k u$ uripe boros, apa-apa selametan terus, tapi mergo adat kebiasaan leluhure ya dilakoni bae amrih selamet, mila niku teng ngriki mboten wonten ingkang gadhah omah gedong" (Orang Kejawen itu hidupnya boros, karena sering selamatan, namun karena ini adat kebiasaan yang dilakukan para leluhur, maka kami lakukan demi mendapatkan keselamatan, karena itu di sini tidak ada yang memiliki rumah gedung [mewah]) (Ridhwan, 2008: 12).

Menurut sebagian komunitas Kejawen, mereka juga meyakini adanya 
alam sesudah alam nyata ini yaitu alam kelanggengan. Hal ini sebagaimana dikatakan oleh Sumitro, "Sak bakdane alam dunya niki wonten alam kelanggengan, selawase, tanpa umur. Menawi tiyang sampun teng alam kelanggengan niku ganti tatahan, nggih meniko tata batin" (Setelah alam dunia ini ada alam baka, selamalamanya tanpa usia. Ketika seseorang telah berada di alam keabadian ia akan berganti menjadi dunia ruh).

Mengenai balasan amal di akhirat, Sumitro menjelaskan, "Menawi manungsa teng alam padhang niki angger mlanggar aturan, nggih besuk badhe tinemu piwales. Gampangipun, yen ora gelem dijiwit, ya aja jiwit. Sebab tiyang gesang niki kedah ngangge planggeran, supaya ora ngrusak pager ayu. Wonten mo limo sing kudu dienggo, lan mo limo sing kudu ditinggalna" (Ketika manusia hidup di dunia dan dia melakukan pelanggaran maka besok akan mendapatkan balasan yang setimpal. Gampangnya, kalau tidak mau dicubit ya jangan mencubit. Sebab manusia hidup ini harus memakai aturan supaya tidak merusak tatanan kehidupan. Ada 5 (lima) M yang harus dilakukan dan ada 5 (lima) M yang harus ditinggalkan).

Menurut Kiai Kunci Karta Wijaya dari Adiraja bahwa komunitas Kejawen ini selain minta ke Gusti Allah (Alloh dibaca Alah), mereka juga minta sesuatu ke Kiai Bonokeling. Ketika ditanya tentang keyakinannya ini dalam beliau menjawab, "Riyin-riyin tuduh seka tiyang sepuh kados niku," artinya, ini ada sejak dulu kala sebagaimana dikatakan oleh orang-orang tua (Ridhwan, 2008: 13).

Dalam konteks relasi sosial antar anggota kelompok komunitas Blangkon adat atau antar kelompok adat dengan masyarakat lainnya (muslim masjid) berjalan secara baik dengan hidup guyub dan rukun. Baik menurut Wiryatpada maupun Arlam, belum pernah terjadi gesekan atau konflik yang bersifat fisik antar warga masyarakat yang dipicu oleh perbedaan paham ini. Bahkan menurut Wiryatpada, kalaupun ada tarikan sumbangan pembangunan masjid anggota masyarakat yang berasal dari kelompok kejawen juga memberikan sumbangan untuk pembangunan masjid. Namun demikian, menurut Arlam terdapat sentimen yang bersifat laten dan di bawah permukaan seringkali kelompok adat (kejawen) memandang kurang simpatik terhadap aktivitas keagamaan terutama terhadap anak-anak mereka. Tidak jarang orang tua dari kelompok adat melarang anaknya untuk mengaji atau shalat di masjid (Ridhwan, 2008: 32).

Dalam melihat masyarakat Islam Kejawen di desa Pekuncen, Banyumas kelompok "Islam lima waktu" berpandangan sebagaimana tergambar dalam 
pernyataan bapak Arlam yang berprinsip "Lakum dinukum wali yadin" (bagimu agamamu, bagiku agamaku). Masing-masing mempunyai keyakinan, sehingga yang penting adalah sikap menghormati. Menurut Arlam sebagaimana pernyataannya, "Saya sendiri orang yang sejak kecil tidak pernah ikut mereka sehingga saya tidak tahu banyak tentang ajaran mereka. Secara aqidah mereka mengaku sebagai orang Islam, percaya adanya Allah dan Muhammad Rasulullah, tetapi mereka tidak melaksanakan syari'at Islam. Bahkan yang justru dijunjung bahkan disembah-sembah adalah nenek moyang mereka yang sering disebut namanya Ki Bonokeling. Sebab akidah mereka itu syirik".

Dalam pandangan Arlam berbagai acara ritual "selamatan" yang mereka adakan hanya sekedar kumpul-kumpul. Tidak ada pengarahan atau wejangan tentang ajaran agama, bahkan cenderung terjadi kemubadziran.

Relasi sosial komunitas Islam Kejawen dengan masyarakat lainnya berjalan secara alamiyah dengan mendasarkan pada tata nilai lokal masyarakat desa pada umumnya dengan ciri masyarakat yang guyub dan rukun. Keyakinan agama diposisikan sebagai hak yang dimiliki oleh setiap manusia dan ia bersifat pribadi. Semangat hidup berdampingan (co-existence) menjadi nilai yang sudah melembaga.

\section{Simpulan}

Dari berbagai uraian tersebut di atas, dapat diambil kesimpulan bahwa wajah Islam di Jawa merupakan hasil dialog dan dialektika antara Islam dan budaya lokal yang kemudian menampilkan wajah Islam yang khas Jawa yang kemudian disebut Islam Jawa. Dalam kenyataannya, Islam di Jawa memanglah tidak bersifat tunggal, tidak monolit, dan tidak simpel. Islam Jawa bergelut dengan kenyataan negara-bangsa, modernitas, globalisasi, kebudayaan lokal, dan semua wacana kontemporer yang menghampiri perkembangan zaman dewasa ini. Dalam konteks ini, respons kelompok-kelompok atau organisasiorganisasi Islam di Indonesia dan Jawa khususnya sangat variatif, mulai dari konservatif, moderat, liberal, radikal, hingga fundamentalis.

Dialog dan dialektika antara Islam dan budaya lokal Jawa dalam bidang sosial sebagai wujud dari bagian tampilnya wajah Islam Jawa di bumi nusantara terlihat dalam berbagai ragam aktivitas sosial umat Islam di Jawa yang merupakan bentuk kearifan lokal berwajah Islam Jawa dalam rangka menampilkan karakter Islam yang tasamuh, tawassuth, dan tawazun. Di antaranya adalah tercermin dalam relasi sosial komunitas Islam Kejawen Banyumas dengan masyarakat lainnya berjalan secara alamiyah dengan mendasarkan pada tata nilai lokal 
masyarakat desa pada umumnya dengan ciri masyarakat yang guyub dan rukun. Keyakinan agama diposisikan sebagai hak yang dimiliki oleh setiap manusia dan ia bersifat pribadi. Semangat hidup berdampingan (co-existence) menjadi nilai yang sudah melembaga.

\section{Daftar Pustaka}

Abdullah, Taufiq. 1989. Islam dan Pembentukan Tradisi Di Asia Tenggara: Sebuah Perspektif Perbandingan. Dalam Taufiq Abdullah dan Sharon Shiddiqui, Tradisi dan Kebangkitan Islam Di Asia Tenggara [hlm 29-30]. Jakarta: LP3ES.

Arnold, Thomas W. 1977. The Preaching of Islam. Jakarta: Wijaya.

Azra, Azyumardi. 1994. Jaringan Ulama, Timur Tengah dan Kepulauan Nusantara Abad XVII dan XVIII. Bandung: Mizan.

Azra, Azyumardi. 1999. Renaisans Islam Asia Tenggara: Sejarah Wacana dan Kekuasaan. Bandung: Rosdakarya.

Drewes, G.W.J. 1989. Pemahaman Baru Kedatangan Islam di Indonesia. Dalam Ahmad Ibrahim, et al., Islam di Asia Tenggara. Perspektif Sejarah [hlm 7-36]. Jakarta: LP3ES.

Geertz, Clifford. 1976. The Religion of Java. Chicago: Chicago University Press.

Graaf, HJ. de. 1989. Islam di Asia Tenggara sampai Abad ke-18. Dalam Azyumardi Azra, Perspektif Islam di Asia Tenggara [hlm 2]. Jakarta: Yayasan Obor Indonesia.

Herusatoto, Budiono. 1987. Simbolisme dalam Budaya Jawa. Yogyakarta: Hanindita.

Koentjaraningrat. 1994. Kebudayaan Jawa. Jakarta: Balai Pustaka.

Koentjaraningrat. 1995. Manusia dan Kebudayaan di Indonesia. Jakarta: Jambatan.

Koentjaraningrat. 1996. Kebudayaan Mentalitas dan Pembangunan. Jakarta: Gramedia Pustaka Utama.

Marzuki. 2006. Tradisi dan Budaya Masyarakat Jawa dalam Perspektif Islam. Kajian Masalah Pendidikan dan Ilmu Sosial "INFORMASI". 32, (1): 2-6. 
http://eprints.uny.ac.id/view/type/article.html. [diakses 13Februari 2012].

Mudzhar, Muhammad Atho. 1990. Fatwas of The Council of Indonesian Ulama A Study of Islamic Legal Thought in Indonesia, 1975-1988. Los Angeles: University of California.

Partokusumo, Karkono Kamajaya. 1995. Kebudayaan Jawa Perpaduannya dengan Islam. Yogyakarta: Aditiya Media.

Pemberton, John. 2003. Jawa. Yogyakarta: Mata Bangsa.

Ricklefs, M.C. 2002. Syekh al Mutamakin dan Sejarah Jawa abad XVIII. Dalam Abdul Milal Bizawie, Perlawanan Kultural Agama Rakyat [hlm xx-xxxi]. Yogyakarta: SAMHA bekerja sama dengan Yayasan Keris.

Ridhwan. 2008. Islam Blangkon; Studi Ethnografi Karakteristik Keberagamaan di Kabupaten Banyumas dan Cilacap. Istiqro'. Volume 07, Nomor 01: 5-6.

Simuh. 1996. Sufisme Jawa. Yogyakarta: Bentang Budaya.

Suyanto. 1990. Pandangan Hidup Jawa. Semarang: Dahana Prize.

Wahid, Abdurrahman. 1982. Bunga Rampai Pesantren. Jakarta: Dharma Bhakti.

Wertheim, W.F. 1989. Islam dan Pembentukan Tradisi di Asia Tenggara: Sebuah Perspektif Perbandingan. Dalam Taufiq Abdullah dan Sharon Shiddiqui, Tradisi dan Kebangkitan Islam di Asia Tenggara [hlm 94-111]. Jakarta: LP3ES.

Woodward, Mark R. 2001. Islam Jawa: Kesalehan Normatif versus Kebatinan. Yogyakarta: LKiS.

el Harakah Vol.14 No.1 Tahun 2012 